\title{
A formação de competências socioemocionais na política nacional de alfabetização: uma análise crítica
}

\author{
The formation of socioemotional competences in the national literacy policy: \\ a critical analysis \\ la formación de competencias socioemocionales en la política nacional de \\ alfabetización: un análisis crítico
}

JANE RIGOLDI DOS SANTOS

http://orcid.org/0000-0001-9477-408X

Universidade Estadual de Maringá

Faculdade de Educação

Departamento de Pedagogia

Maringá, PR, Brasil

JULIANA PIOVESAN VIEIRA

http://orcid.org/0000-0002-8129-5474

Universidade Estadual de Maringá

Faculdade de Educação

Departamento de Pedagogia

Maringá, PR, Brasil

MARLI DELMONICO DE ARAUJO FUTATA

http://orcid.org/0000-0002-0058-7177

Universidade Estadual de Maringá

Faculdade de Educação

Departamento de Pedagogia

Maringá, PR, Brasil

Resumo: $\mathrm{O}$ artigo discute a inclusão da formação socioemocional na Política Nacional de Alfabetização (PNA), expressa no decreto $n^{\circ} 9.765 / 2019$, e sua vinculação com as propostas do Instituto Ayrton Senna (IAS), apresentadas no documento "Alfabetização $360^{\circ}$ ". O objetivo é apresentar a concepção de alfabetização difundida pelo IAS e como esta representa a manutenção da precarização do processo de alfabetização no Brasil, ao trazer elementos secundários do processo de ensino e aprendizagem, como primários, neutralizando e dissolvendo a função da escola pública. Amparados pelo referencial teórico do materialismo histórico-dialético, entendemos que nenhuma prática de alfabetização é neutra, mas envolta por lutas, disputas de interesses, que tanto podem propor perspectivas de alfabetização que contribuam para a superação da sociedade capitalista, como também, de modo contraditório, como a "Alfabetização $360^{\circ "}$ ", podem propor a adaptação, ao reafirmar a formação de comportamentos amáveis, resilientes, condizentes com as necessidades do capital em um contexto de crise social e produtiva. Para desenvolver o artigo, realizamos uma pesquisa documental e bibliográfica de análise de documentos legislativos brasileiros (PNA), relatórios de organizações internacionais (UNESCO), folheto 
do IAS, artigos científicos e textos de autores da psicologia histórico-cultural. A conclusão a que chegamos é: está em curso um processo de reconfiguração do que entendemos ser alfabetização, direcionado pelo IAS, para o qual alfabetizar é mais do que ler e escrever textos, mas deter capacidades de leitura e regulação de emoções, pontuada como competência socioemocional. Há um processo de reconfiguração do conceito de alfabetização, que em nosso entendimento deve ser refutado.

Palavras-chave: Alfabetização. Competências socioemocionais. Instituto Ayrton Senna.

Abstract: The article discusses the inclusion of socioemotional formation in the National Literacy Policy, expressed in Decree No. 9.765/2019, and its link with the proposals of the Ayrton Senna Institute (LAS), presented in document $360^{\circ}$ Literacy. The objective is to present the concept of literacy disseminated by LAS; and to reflect on the fact that this proposal will harm the literacy process in Brazil, by bringing secondary elements of the teaching and learning process, as primary, neutralizing and dissolving the function of the public school. Supported by the theoretical framework of historical dialectical materialism, it is understood that no literacy practice is neutral, but surrounded by struggles, disputes of interests, which can both propose literacy perspectives that contribute to the overcoming of capitalist society. As well, in a contradictory way, such as Literacy $360^{\circ}$, they can propose adaptation, by reaffirming the formation of kind and resilient behaviors, consistent with the needs of capital in a context of social and productive crisis. To develop the article, a documentary and bibliographic research was carried out to analyze Brazilian legislative documents (PNA), reports from international organizations (UNESCO), LAS leaflet, scientific articles, and texts by authors of HistoricalCultural Psychology. The conclusion reached is: a process of reconfiguring what we understand to be literacy is underway, directed by the LAS, for which literacy is, more than reading and writing texts, having reading and regulation skills, punctuated as a socioemotional competence. There is a process of reconfiguring the concept of literacy, which in our understanding must be refuted.

Keywords: Literacy. Socioemotional competences. Ayrton Senna Institute.

Resumen: El texto discute la inclusión de la capacitación socioemocional en la Política Nacional de Alfabetización, expresada en el Decreto No. 9,765 / 2019, y su vínculo con las propuestas del Instituto Ayrton Senna (LAS), presentadas en el documento Alfabetización $360^{\circ}$. El objetivo es presentar el concepto de alfabetización difundido por IAS; y para advertir el hecho de que esta propuesta perjudicará el proceso de alfabetización en Brasil, al incorporar elementos secundarios del proceso de enseñanza y aprendizaje, como primarios, neutralizando y disolviendo la función de la escuela.

Palabras clave: Alfabetización. Habilidades socioemocionales. Instituto Ayrton Senna. 


\section{INTRODUÇÃO}

A questão da alfabetização é uma temática presente no campo da política em âmbito global. Está presente nos debates das organizações internacionais, como a Organização das Nações Unidas para Educação, Ciência e Cultura (UNESCO), que desde 1946 prescreve orientações, reafirmando a importância da alfabetização para todos (UNESCO, 2020). A alfabetização é destacada, no que tem sido interpretado como "uma agenda globalmente estruturada para educação" (DALE, 2004, 426). Nesse sentido, o debate realizado indica que aumentar os níveis de alfabetização das populações pobres é uma possibilidade de amenizar os impactos da pobreza extrema.

A UNESCO é uma organização que representa os interesses econômicos do sistema capitalista e uma das principais organizações orientadoras de políticas relativas à alfabetização; produz materiais, estudos, índices e estatísticas sobre a alfabetização e o analfabetismo em todo o mundo. Desse modo, enfatiza a necessidade de investimentos massivos em alfabetização, especialmente, para os grupos vulneráveis, ou seja, mulheres, crianças e jovens que não tiveram acesso à educação na idade adequada. Essa condição pode ser confirmada pelo relatório "Educação para Todos: o compromisso Dakar", chancelado na África, no ano 2000, cujo objetivo foi chamar a atenção de governos mundiais para as metas estabelecidas, neste caso, para a alfabetização. Naquele momento, 880 milhões de pessoas desertavam em condições de analfabetismo, sendo a maioria mulheres (UNESCO, 2001). No referido documento, ficou registrada a necessidade da ampliação de $50 \%$ das taxas de alfabetização, especialmente entre a população adulta e feminina e, além de ampliar o acesso das mulheres a essa condição, deveriam ser criados mais instrumentos de medição de resultados em alfabetização, aritmética e determinadas habilidades para a vida (UNESCO, 2001).

A ideia disseminada pela UNESCO é a de que, ao atingir metas relativas à alfabetização de suas populações, os Estados nacionais se tornam mais competitivos por meio da qualificação de um capital humano mais adequado às demandas de produtividade do modo econômico capitalista, dando aos seus países de origem condições de concorrer no mercado global. Um dos eixos para se garantir a política de "Educação para Todos" (EPT), proposta pela UNESCO, é desenvolver políticas públicas de combate ao analfabetismo, como uma forma de promover o que descrevem como empoderamento de populações que vivem em condições de pobreza: 
A alfabetização empodera as pessoas e as capacita para poderem participar de forma plena na sociedade e a contribuir com o aprimoramento dos meios de sobrevivência. A alfabetização também impulsiona o desenvolvimento sustentável, possibilitando assim maior participação no mercado de trabalho, melhoria da saúde e da nutrição das crianças e da família, além de reduzir a pobreza e expandir as oportunidades na vida. (UNESCO, 2020, s/pág., grifo nosso).

Neste caso, a perspectiva que permeia as orientações da UNESCO para alfabetização estabelece esta como um ponto central para que as pessoas tenham condições de criar maneiras de sobreviver, mesmo em precárias condições de vida. Ser alfabetizado implicaria em desenvolver determinados comportamentos, tais como: maior capacidade de diálogo, de empatia, compreensão pelo ponto de vista alheio e, consequentemente, maiores chances de manutenção de coesão social, diminuindo, assim, a criminalidade e a violência, tendo em vista que pessoas alfabetizadas têm mais capacidade de planejamento do cotidiano, são mais capazes de desenvolver hábitos de higiene, cuidado com a vida sexual, planejamento familiar, entre outros.

Em sintonia com essas proposições internacionais, o Plano Nacional de Educação (PNE) - com vigência prevista de 2014 até 2024 - indica a necessidade de combate ao analfabetismo, por meio da garantia da alfabetização dos estudantes até o $3^{\circ}$ ano do ensino fundamental. Em sua meta 5, o PNE determina que é preciso: "alfabetizar todas as crianças, no máximo, até o final do terceiro ano do ensino fundamental” (BRASIL, 2014, p. 58). Essa meta dá uma resposta a problemas históricos da realidade educacional brasileira:

Os dados estatísticos são preocupantes, uma vez que, no censo de 2010, constatou-se que $15,2 \%$ das crianças brasileiras com 08 anos de idade que estavam cursando o ensino fundamental eram analfabetas, considerando que o índice de não alfabetizados era de 12,8\% para pessoas de 10 anos ou mais. De qual fenômeno estamos tratando? Acompanhando os censos, desde sua instituição no Brasil até os dias atuais (1872 a 2000), é possível observar que levamos mais de cem anos para mudar o índice de analfabetismo de $82,3 \%$ para a população em geral e de aproximadamente $78 \%$ para crianças de até 10 anos, para o seu reverso, $87,2 \%$ de alfabetismo. Trata-se, portanto, de um processo lento para regressão dos índices. Além disso, temos que considerar quem está fora da escola ou quem ficou pouco tempo nela. Embora tenhamos alcançado este resultado, acompanhando os censos recentes e os dados das avaliações em grande escala, constatamos, como sempre, que o analfabetismo anda junto com desigualdades sociais e regionais. (FRADE, 2018, p. 23-24, grifos nossos). 
Para atingir a meta 5, o PNE pontua estratégias, como: valorização e formação de professores alfabetizadores; fomento à produção de tecnologias relativas a métodos de alfabetização; práticas inovadoras; além de processos de avaliação da alfabetização dos estudantes (BRASIL, 2014). Em sua meta 9, o PNE determina a necessidade de:

[...] elevar a taxa de alfabetização da população com quinze anos ou mais para noventa e três inteiros e cinco décimos por cento até 2015 e, até o final da vigência deste PNE, erradicar o analfabetismo absoluto e reduzir em cinquenta por cento a taxa de analfabetismo funcional. (BRASIL, 2014, p. 68).

No entanto, como nos alerta Frade (2018), todas essas ações são relevantes, porém o problema do analfabetismo no Brasil não se resolve via legislação, sendo essencial desenvolver políticas que abarquem transformações sociais mais amplas. A esse respeito, Machado (2018) afirma que o plano interpreta de forma equivocada o analfabetismo da população adulta brasileira, compreendendo-o como um mal que pode ser arrancado pela raiz, desconsiderando as dimensões históricas e sociais que perpassam a questão, intrinsicamente relacionadas às condições de desigualdade do nosso país. A legislação apresenta uma visão idealista de que seria possível eliminar o analfabetismo via metas, mas sem ações efetivas no âmbito social.

A partir desse contexto, o objetivo do presente trabalho é contribuir para fomentar o debate científico acerca da atual Política Nacional de Alfabetização (PNA) e sua vinculação com o discurso sobre a educação integral, articulado com a formação de competências socioemocionais.

Para desenvolver este artigo, realizamos estudos documental e bibliográfico. De modo geral, nos reportamos à análise, por exemplo, da PNA (2019); em documentos do Instituto Ayrton Senna (IAS, 2017, 2019?); nos estudos de Alves (2011), que pontua a precarização do mundo do trabalho; em autores que defendem a educação pública e a alfabetização comprometida com a transformação social, como Gasparin (2002) e Saviani (2005); e em autores da psicologia histórico-cultural, como Vigotski (1998, 2000) e Leontiev (2004, 2005), que defendem a importância do conhecimento para o desenvolvimento da consciência humana.

O artigo se pauta no referencial teórico-metodológico materialista histórico-dialético, que permite compreender os processos de alfabetização como socialmente produzidos e reconfigurados, a partir do modo em que os homens produzem sua existência. A produção da linguagem falada e escrita resultou 
de um longo processo de intercâmbios dos homens entre si e com a natureza, determinante para produção da consciência humana, tendo em vista que nosso pensamento é verbal:

[...] a linguagem é a consciência real prática que existe também para outros homens e que, portanto, só assim existe também para mim; e a linguagem só nasce, como a consciência, da necessidade [...], da necessidade orgânica [...] do intercâmbio com outros homens. (MARX; ENGELS, 2009, p. 44).

A partir dessas considerações, entendemos que os processos de alfabetização estão relacionados ao processo de trabalho, haja vista que as demandas pela formação escolarizada de determinadas competências, são originadas pela objetividade presente no interior do processo de produção capitalista de base flexível. Diante dessas considerações, na primeira seção do texto, interpretamos os nexos da formação socioemocional, que se apresenta como inovadora, buscando explicitar o ponto em que ela converge com os direcionamentos de práticas alfabetizadoras. Em seguida, analisamos a concepção de alfabetização difundida pelo IAS, no documento "Alfabetização $360^{\circ}$ na perspectiva da Educação Integral", desvelando seus fundamentos e apresentando algumas considerações sobre o impacto dessas proposições no âmbito da formação escolar pública brasileira.

\section{A FORMAÇÃO SOCIOEMOCIONAL E SEUS VÍNCULOS COM A QUESTÃO DA ALFABETIZAÇÃO}

Para entender a inclusão da formação socioemocional na PNA, é preciso analisar um protagonista no processo de produção dessas orientações: o IAS, que, desde 2013, tem empreendido esforços em parceria com o Movimento Todos pela Educação, em favor da formação socioemocional (SANTOS, 2015). O IAS (2019?, p. 11) define competências socioemocionais como:

Características que todas as pessoas possuem, em níveis diversificados, que envolvem a capacidade de mobilizar, articular e colocar em prática conhecimentos, valores, atitudes e habilidades para se relacionar consigo mesmo e com os outros, para estabelecer e atingir objetivos, para tomar decisões e enfrentar situações adversas ou novas. Por exemplo: a colaboração, a assertividade e a resiliência. (Grifos nossos). 
Em parceria com a Organização para a Cooperação e Desenvolvimento Econômico (OCDE), esse instituto tem influenciado a elaboração da política educacional brasileira tanto nas orientações curriculares, quanto na política de financiamento educacional ${ }^{1}$.

O IAS é um grande produtor de materiais pedagógicos, instrumentos de avaliação e assessorias que são ofertadas às redes de ensino. Acreditamos que essa organização vem orientando a produção e implementação da política nacional de alfabetização para dar fôlego aos seus programas, bem como para ganhar visibilidade e comercializar produtos educacionais, conforme afirmam no documento: "O IAS disponibiliza uma trilha sistematizada para colaborar com as redes de ensino em um dos principais passos rumo à implementação da Base Nacional Comum Curricular (BNCC) nas escolas: a construção de um currículo compromissado com a educação integral.” (IAS, 2019?, p. 7). Esse fato permite-nos constatar que o instituto retoma, no âmbito do fazer pedagógico, a divisão entre o trabalho manual e o intelectual, ou seja, concebe redes de ensino e professores como meros executores de métodos de ensino (pensados por uma "elite intelectual"), tornando-os profissionais alijados da totalidade do processo de seu trabalho.

Em sintonia com essas orientações formativas, a Base Nacional Comum Curricular (BNCC) para o ensino fundamental, aprovada em 2017, assevera a relevância de formar competências socioemocionais, afirmando que competência se trata de: "mobilização de conhecimentos (conceitos e procedimentos), habilidades (práticas, cognitivas e socioemocionais), atitudes e valores para resolver demandas complexas da vida cotidiana, do pleno exercício da cidadania e do mundo do trabalho." (BRASIL, 2017, p. 8). As orientações indicam que devemos formar pessoas empregáveis para atuar em um mundo onde existe espaço para poucos, ou seja, somente para os melhores, e:

Também é necessário que o trabalhador esteja disponível para incorporar à sua rotina de trabalho árdua e desgastante muitas horas de trabalho, caso seja necessário. [...] A flexibilização da mão-de-obra passa a ser outro requisito essencial [...] é preciso ser polivalente para assumir qualquer posto que se faça necessário. Baseado neste princípio de multifuncionalidade foi deflagrada nas últimas décadas a teoria das competências, onde o indivíduo precisa desenvolver uma série de capacidades para se inserir ou se manter no mercado de trabalho. (FUTATA, 2005, p. 4, grifos nossos).

1 A este respeito ver Carvalho (2017), que trata sobre os novos arranjos de desenvolvimento educacional, descritos como novos caminhos jurídicos, usados por organizações não governamentais (ONGs), organizações da sociedade civil de interesse público (OCIPs), fundações e institutos para conseguirem captação de recursos públicos. 
Ser competente implica em saber fazer - um conceito que nos remete à linguagem do patrão para o empregado, ao julgar seu operário como competente ou seu contrário, incompetente (SANTOS, 2015). A PNA, diante disso, foi elaborada a partir dessas orientações, prescrevendo que competências socioemocionais como resiliência, empatia, responsabilidade, extroversão e abertura a novas experiências - sejam disseminadas como características individuais que contribuem para o melhor desenvolvimento interpessoal e intrapessoal (SANTOS; PRIMI, 2014) e que, portanto, demandam uma formação que estimule:

Imaginação criativa - É capaz de gerar novas maneiras de pensar e agir por meio da experimentação, brincadeira, aprendendo com seus erros, com visão.

Responsabilidade - Tem habilidades de autorregular o que precisa para completar as suas responsabilidades, cumprir seus compromissos, agir de maneira confiante e consistente, e inspirar confiança. Essa faceta tem uma conexão com Amabilidade e deve ser importante para predizer o envolvimento cívico e comprometimento.

Tolerância a frustração - Tem estratégias efetivas para regular frustração, raiva e irritação; é capaz de manter a tranquilidade e serenidade em face a frustrações, não é volátil.

Entusiasmo - Capaz de demonstrar paixão e empolgação pela vida; vai ao encontro a suas atividades diárias com energia, entusiasmo e uma atitude positiva. Empatia - Capaz de assumir a perspectiva dos outros e de utilizar habilidades de empatia para entender as necessidades e sentimentos dos outros, agindo com generosidade e consideração de acordo com essa percepção, constrói relacionamentos próximos ao ajudar, apoiar e dar assistência tanto material quanto emocional; é uma pessoa generosa e de fácil convívio. (IAS, 2017, p. 29-46).

A partir dessas orientações que norteiam a política educacional do país, o governo atual apresentou o decreto $\mathrm{n}^{\circ}$ 9.765, de 11 de abril de 2019, como orientador da PNA. Nesse documento, a dimensão socioemocional é destacada como um dos princípios dessa política, como explicita o artigo $3^{\circ}$ :

VII - reconhecimento de que o desenvolvimento integral da criança pressupõe a inter-relação e a interdependência dos domínios físico, socioemocional, cognitivo, da linguagem, da literacia e da numeracia;

VIII - aprendizagem da leitura, da escrita e da matemática básica como instrumento de superação de vulnerabilidades sociais e condição para o exercício pleno da cidadania (BRASIL, 2019, p. 2, grifos nossos).

Como vemos, a dimensão socioemocional ganhou um efeito de obrigatoriedade na PNA. Ao ressaltar o caráter pragmático e instrumental do processo de alfabetização, situando-o como instrumento de superação da vulnerabilidade social, observamos uma total sintonia entre as proposições 
da UNESCO e os princípios dessa política. A respeito da utilização do termo "vulnerabilidade social", Almeida (2018) entende que sua utilização oculta aspectos relativos à desigualdade social provocada pelo modo de produção capitalista.

\section{“ALFABETIZAÇÃO 360": UMA PROPOSTA DO IAS PARA A EDUCAÇÃO PÚBLICA}

O IAS tem atuado na elaboração da BNCC, a partir da perspectiva da formação integral, ou seja, aquela que contempla tanto a formação cognitiva como a formação socioemocional. O documento "Alfabetização 360 " apresenta uma proposta na qual o processo de alfabetização seja capaz de promover um giro de $360^{\circ}$, o que sugere a ideia de uma formação completa. A nosso ver, essa é uma metáfora incoerente, já que uma volta de $360^{\circ}$ retorna ao lugar de partida.

Para compreendermos o teor dessa formação proposta pelo instituto, analisamos o documento intitulado "Alfabetização $360^{\circ}$ na perspectiva da Educação Integral" (2019?). Nesse texto, o instituto chama a atenção para a necessidade de uma educação que promova "mais do que o domínio de técnicas e conteúdos acadêmicos [para] acompanhar os desdobramentos das inovações no dia a dia da sociedade 5.0, altamente integrada pelos serviços inteligentes" (IAS, 2019?, p. 3). O documento parte dessa ideia para defender a inclusão da formação das competências socioemocionais no currículo escolar, desde a educação infantil. $\mathrm{O}$ aparente paradoxo presente nessa ideia não encontra eco numa análise mais profunda acerca da função da escola pública, apresentada pelo "Currículo Básico para a Escola Pública do Estado do Paraná” (PARANÁ, 1990, p. 15), o qual assevera que: "o conhecimento científico deve ser tomado como o elemento básico de referência para a organização do ensino.” Para o IAS, o grande volume de informações e a complexidade das relações humanas são demandas que exigem a construção de práticas de alfabetização inovadoras, capazes de contribuir para uma leitura do mundo atual, promover soluções sustentáveis e formar para o enfrentamento de desafios, que são individuais e coletivos. Todavia, entendemos que a educação escolar, que pode atingir tais objetivos, é exatamente aquela em que o saber científico se faz presente. 
Claro está que não se trata de qualquer saber, trata-se da forma mais articulada, de maior capacidade explicativa, daquele saber através do qual se dê a explicação mais orgânica dos elementos que compõe a prática social. Se almejamos que o aluno, ao final de sua escolarização elementar, possua os instrumentos necessários (conhecimentos) para compreender, elaborar e expressar uma visão de mundo mais articulada, menos mágica e folclórica do que aquela que detém no início deste processo, não será com o domínio de um conhecimento que dê conta de explicar a parte, sem articulá-la com o todo, que iremos dar qualidade ao ensino. (PARANÁ, 1990, p. 15).

Segundo o IAS, mais do que conteúdos acadêmicos, o trabalho pedagógico deve voltar-se para o desenvolvimento de competências, em especial as socioemocionais. Nessa proposta, a alfabetização se constitui em um componente estratégico, pois:

Em nossa sociedade letrada, a alfabetização é pilar fundamental e estratégico para todas as demais conquistas do processo de formação de crianças e jovens, e essencial para o desenvolvimento pleno ao longo da vida. [...] neste sentido, é preciso enxergar que o domínio de habilidades de leitura e escrita é, também, uma oportunidade única para o desenvolvimento de um amplo conjunto de competências. (IAS, 2019?, p. 6, grifos nossos).

Assim, perde-se de vista ou mascara-se a apropriação da leitura e da escrita como condição sine qua non à formação humana e como instrumento fundamental de inserção social. O documento afirma, ainda, que o não domínio da leitura e da escrita "compromete uma atuação mais crítica e cidadã" (IAS, 2019?, p. 6, grifos nossos). Entretanto, a criticidade proposta nessa afirmação do documento se apresenta bastante limitada, pois não há referência, durante todo o texto, a uma concepção de cidadania que indique o direito às condições objetivas necessárias, ou seja, o acesso aos bens materiais, culturais e simbólicos, fundamentais à subsistência e ao desenvolvimento de uma formação que possibilite uma atuação crítica e cidadã. Pelo contrário, o que é possível inferir é a indicação de uma cidadania vinculada à atuação no mundo trabalho e a esfera social em uma perspectiva de cidadania ativa, onde o sujeito atua em sua comunidade, mas sem exigir direitos sociais ao Estado (GARCIA, 2015).

Investir nessas competências socioemocionais, desde os primeiros anos da vida escolar, aumentaria a autoestima dos estudantes, a capacidade para lidar com frustrações, desenvolvendo a atenção, a memória e a força emocional; consequentemente, o desempenho no processo de alfabetização poderia ser mais eficiente. A partir desse pressuposto, o IAS faz prescrições gerais para influenciar a política de alfabetização no âmbito da educação pública brasileira, entre as quais destacamos: 
As propostas de alfabetização que realmente podem apoiar a formação de crianças para serem protagonistas no século 21 devem ser construídas com a perspectiva da educação integral. Daí a importância de se disseminar propostas com avanços concretos nos primeiros anos do Ensino Fundamental, o que se torna, também, condição para que a educação integral ocorra nas etapas seguintes. (IAS, 2019?, p. 6, grifos nossos).

É pertinente alertarmos para o fato de que o conceito de educação integral, uma demanda, que advém dos movimentos sociais, tem sofrido uma reconfiguração realizada pelo IAS. Compreendemos que não está em jogo o aumento do tempo de permanência do estudante na escola, somado a uma formação que considere o homem como um todo, permitindo acesso à arte, à literatura, à ciência, às capacidades de compreensão e produção de tecnologias e pesquisa, mas reforçar uma formação minimamente acadêmica, com o reforço aos aspectos emocionais do estudante, no caso, como afirmam, considerando dimensões cognitivas e socioemocionais, conforme descrito no documento:

[...] o conceito de educação integral que se coloca está relacionado menos ao aspecto de tempo e mais ao propósito das atividades de ensino e aprendizagem. [...] defendemos a visão de alfabetização $360^{\circ}$, que amplia a perspectiva de desenvolvimento da língua materna e traz a essência da educação integral. Isso implica em um trabalho intencional com diferentes dimensões humanas (intelectual, física, socioemocional), e em articular a apropriação do sistema de escrita alfabético com o desenvolvimento de competências socioemocionais e múltiplas linguagens. A alfabetização $360^{\circ}$ é prérequisito para o desenvolvimento humano. (IAS, 2019?, p. 12; 15, grifos nossos).

Na perspectiva do IAS, a educação é uma mercadoria que dificilmente proporcionará uma efetiva valorização dos alunos. Isso porque, em nosso ponto de vista, valorizar os alunos implica em reafirmar uma educação comprometida, primeiramente com conhecimentos socialmente produzidos e não com a centralidade da formação de competências socioemocionais.

O trabalho com as linguagens científica, corporal, artística e tecnológica tem seu lugar garantido no processo de apropriação da língua escrita e leitura, entretanto, o desenvolvimento intelectual ocorre por meio da aprendizagem dos conteúdos escolares, de modo especial, por meio da apropriação de conceitos científicos, ou seja, conteúdos consolidados na linguagem. Assim, os caminhos da aprendizagem devem seguir o objetivo de apropriação dos conhecimentos científicos (VIGOTSKI, 2000). Não basta ensinar a leitura das reações faciais, dos comportamentos, da entonação de voz dos alunos em sala de aula, para que a comunicação possa ser mais eficaz, tendo em vista as capacidades definidas 
como alfabetização emocional ${ }^{2}$. Nas palavras de Saviani (2005, p. 14): “a escola diz respeito ao conhecimento elaborado e não ao conhecimento espontâneo; ao saber sistematizado e não ao saber fragmentado; à cultura erudita e não à cultura popular.” Leontiev (2005, p. 94) explica que o processo de apropriação é:

[...] um fenômeno ativo. Para "se apropriar" dos fenômenos é preciso empreender uma atividade adequada ao conteúdo no objeto ou no fenômeno dado. [Exemplificando] [...] quando dizemos [...] que a criança "assimila" instrumentos, isto significa que começa a usá-los com precisão, que forma as correspondentes ações e operações motoras e mentais.

Assim, “a assimilação no homem é um processo de reprodução, nas propriedades do indivíduo, das propriedades e aptidões historicamente formadas na espécie humana." (LEONTIEV, 2004, p. 288). A linguagem escrita é um resultado da atividade intelectual humana, que carrega nela plasmada o conteúdo e a forma (os processos de codificação e decodificação). Essas características a tornaram um "simbolismo de segunda ordem, que compreende a criação de sinais escritos representativos dos símbolos falados das palavras.” (VIGOTSKI, 1998, p. 153). Logo, a sua assimilação requer compreensão do conteúdo da linguagem e da sua função simbólica. Nessa perspectiva, a aprendizagem da linguagem escrita é fonte de desenvolvimento do psiquismo:

Com efeito, a aprendizagem da leitura e da escrita consiste em compreender a função simbólica dos signos escritos e a assimilação das faculdades formadas em sua elaboração. É ao mesmo tempo um processo de formação ativa, porque permite o desenvolvimento de funções psíquicas novas, funções psicológicas superiores que "hominizam" os indivíduos na esfera cognitiva. (VIEIRA, 2012, p. 45).

A assimilação da linguagem escrita desenvolve o psiquismo humano, porque potencializa a memória, o registro de informações, a transmissão de pensamentos, conceitos e possibilita o acesso aos conhecimentos científicos objetivados nos signos escritos (VIEIRA, 2012). As vivências ou experiências dos alunos servem como um ponto de partida, em um processo contínuo de ação-

A este respeito ver os escritos de Goleman (2011). Outros autores reafirmam a importância da educação socioemocional, como o terapeuta Renato M. Caminha (2014), com o título "Educar crianças: as bases de uma educação socioemocional - um guia para pais, educadores e terapeutas", neste guia o autor pontua a formação socioemocional, como o manejo das emoções como uma tarefa importante para resolução de conflitos e problemas sociais. O que nos permite compreender que os antagonismos de classe que colocam os homens e mulheres uns contra os outros, nesta proposição ficam resumidos apenas à incapacidade de amar e regular emoções. Com essa interpretação, em vez de buscarmos a superação da relação social capitalista, que fragmenta a sociedade, deveríamos ensinar a reconciliação universal entre sujeitos, ocultando a própria dinâmica da relação geradora de profundos problemas sociais, como o individualismo, pobreza, violência, vícios, patologias emocionais, entre outros. 
reflexão-ação (GASPARIN, 2002). Nesse movimento, o aluno deve extrapolar a vivência imediata e ampliar cada vez mais seus conhecimentos. Caso contrário, corremos o risco de realizar, enquanto professores alfabetizadores, uma formação empobrecida.

A aprendizagem dos conceitos científicos possibilita aos estudantes a emissão de opiniões que ultrapassem seu conhecimento imediato, sendo capazes de realizar análises, generalizações e inferências, mediadas por conhecimentos. A leitura possibilita o acesso aos conhecimentos objetivados na escrita, porém apenas saber ler não garante ao educando a assimilação do conhecimento. A escola deve possibilitar a aprendizagem do conhecimento científico, porque ele é o meio para o desenvolvimento do pensamento conceitual (VIEIRA, 2012). A partir do exposto, a apropriação da linguagem escrita e dos conceitos científicos atribui ao ensino o caráter promotor de desenvolvimento cognitivo, uma vez que se criam, no estudante, "órgãos fisiológicos do cérebro", os quais são, nas palavras de Leontiev (2004, p. 289):

[...] órgãos que funcionam da mesma maneira que os órgãos habituais, de morfologia constante, mas distinguem-se por serem neoformações que aparecessem no decurso do desenvolvimento individual (ontogenético). Eles constituem, portanto, o substrato das aptidões e funções específicas que se formam no decurso da apropriação pelo homem do mundo dos objetos e fenômenos criados pela humanidade, isto é, da cultura.

Analisamos que a competência para leitura que está explícita nas propostas do IAS tem compromisso com uma formação funcional de pessoas capazes de ler manuais, reconhecer a linguagem da sociedade de maneira simplificada para uma atuação no cotidiano, sem com isso desenvolver capacidades de interpretação crítica da realidade, das desigualdades sociais, ou melhor, do funcionamento do modo de produção capitalista.

Essa perspectiva alinha-se às necessidades do modelo de produção flexível, que não mais exigem qualificação para o trabalho, e sim empregabilidade, ou seja, uma formação polivalente de pessoas que não dominam nenhuma profissão, mas que possuam capacidades para migrar de emprego em emprego, sem necessariamente possuir conhecimentos de forma profunda, mas que possuam força emocional para suportar essa dinâmica de exploração. Nessa vertente, os sujeitos são responsáveis pela produção de seu projeto de vida, apresentam seu portfólio de competências para vender no mercado, e a escola, por sua vez, deve promover um processo de alfabetização, em sintonia com as exigências do mercado, como ratifica o IAS: 
Educar, de acordo com essa visão, é criar oportunidades para que o estudante possa se desenvolver como um todo, com autonomia, ou seja, empreender ele próprio a construção do seu projeto de vida. Por isso, muito mais do que garantir acesso e conclusão do ensino, o desafio para uma educação de qualidade é conciliar o desenvolvimento de habilidades cognitivas com as competências relacionais e pessoais - também chamadas de socioemocionais. (IAS, 2019?, p. 10, grifos nossos).

A dimensão socioemocional, neste momento, implica em conciliar formação comportamental e emocional, em conjunto com os processos de ensino da língua escrita e da leitura. Ao ensinar os mecanismos para apropriação da linguagem, o professor deve enfatizar temáticas como: respeito à diversidade, meditação, educação nutricional, respeito e tolerância à diversidade cultural, reforçando valores sociais, que estão desgastados e que colocam em risco o ordenamento social capitalista. Como afirmam Vieira e Santos (2018, p. 11):

Ao sofrer ajustes para atender interesses que não visam o desenvolvimento humano, mas a adaptação dos sujeitos, a organização do ensino oferecida nas escolas não garante a aprendizagem da linguagem escrita, mas formas de pensar e agir conforme o ideário mercadológico.

Diante dessas afirmações, a escola deve ser um espaço onde o aluno constrói seu projeto de vida, para que depois, ao fracassar, sem trabalho, mesmo que com competências socioemocionais, seja ele responsável por suas condições, desconsiderando a dinâmica do modo capitalista, que tenta tornar a força de trabalho viva desnecessária no processo produtivo. Como vemos, em um contexto perpassado pelo aumento exponencial da pobreza, desemprego, violência e criminalidade, o processo de alfabetização deve buscar ensinar o diálogo, a tolerância e a concórdia entre as pessoas, evitando uma implosão do sistema.

\section{CONSIDERAÇÕES FINAIS}

Como pudemos observar, os conteúdos que perpassam a alfabetização, bem como o modo em que é direcionada, seus métodos e processos, não seus neutros, mas historicamente condicionados, porque extrapolam a ação escolar, estando diretamente relacionados às necessidades de reprodução do capital. Em um contexto marcado pela desagregação social, vem ao encontro do modo de produção capitalista uma perspectiva de formação que aponte para educar um 
sujeito: amoroso, resiliente, responsável, estável emocionalmente e aberto ao novo. Essa abertura ao novo é entendida como uma capacidade de adaptação à reestruturação da presente fase do sistema capitalista.

Desse modo, em um mundo que permite o encontro de sujeitos diversos, que convivem em uma aldeia global, marcada pelo aumento da pobreza, da escassez de trabalho, é pertinente que saibam se comunicar, seja oralmente ou por escrito, ou que saibam ler materiais escritos, para refletir melhor como agir em situações conflitivas, mas que, por outro lado, não extrapolam os problemas do cotidiano, nem interpretam os limites da sociedade capitalista. A leitura dos comportamentos dos outros, bem como o autoconhecimento, passa a fazer parte do que determinam ser uma alfabetização emocional.

Alfabetizar pessoas, neste momento, ganha significados variados, sendo sua função dar às pessoas determinadas características comportamentais, que as habilitarão para sobreviver em um mundo de incertezas, sendo capazes de empreender, usar a criatividade em contextos e situações variadas, sendo empresários do seu próprio eu, uma espécie de empresa de si mesmo.

Desse modo, concordamos com Ciervo e Silva (2019), ao diagnosticarem estar em moda um processo de emocionalização da ação pedagógica que marca os processos de alfabetização, defendendo a ideia de que, ao considerar os aspectos socioemocionais, contribuiremos para alavancar a aprendizagem dos alunos. No entanto, não desconsideramos a importância de valorizar os alunos, porém devemos considerar que valorizar o estudante é um aspecto já realizado pelos professores, bem como considerar seus afetos, emoções e sentimentos. Todavia, isso é um fator intrínseco à ação escolar, logo, não será preciso avaliação para essa dimensão, nem mesmo manuais para ensinar aos professores a valorizar seus alunos, ou reafirmar sua autoestima e autocontrole durante a o processo de alfabetização.

Entendemos que os professores alfabetizadores, ao trabalharem a dimensão socioemocional de forma intencional, terão mais funções a realizar, principalmente se tiverem que planejar e avaliar essa dimensão, um aspecto que poderá agravar ainda mais o processo de alfabetização dos alunos, tendo em vista a sobrecarga de tarefas docentes. Além disso, precisamos analisar o fenômeno em sua essência. Como vemos, o IAS, em nosso entendimento, depende do fracasso escolar para oferecer seus programas de aceleração e correção de fluxo, apropriando-se do fundo público das redes municipais de ensino, ou seja, a manutenção da precarização da alfabetização é do interesse dessa instituição e demais grupos privatistas, aos quais se associa e representa. $\mathrm{O}$ analfabetismo gerado pela precarização da educação pública e condições de pobreza vividas 
pela população brasileira é uma mercadoria geradora de lucro para aqueles que propõem soluções educacionais inovadoras, entre as quais encontra-se a "Alfabetização $360^{\circ "}$.

\section{REFERÊNCIAS}

ALMEIDA, Melissa Rodrigues de. A formação social dos transtornos do humor. 2018. 415 f. Tese (Doutorado em Saúde Coletiva) - Faculdade de Medicina de Botucatu, Universidade Estadual Paulista Júlio de Mesquita Filho, Botucatu, 2018.

ALVES, Giovanni. Trabalho e subjetividade: o espírito do toyotismo na era do capitalismo manipulatório. São Paulo: Boitempo, 2011.

BRASIL. Plano Nacional de Educação - PNE e dá outras providências. Lei no 13.005, de 25 de junho de 2014. Aprova o Diário Oficial da União, Brasília, DF, 26 jun. 2014b. Edição extra. Disponível em: http://www.planalto.gov.br/ccivil_03/_ ato2011-2014/2014/lei/113005.htm. Acesso em: 18 out. 2014.

BRASIL. Base Nacional Comum Curricular Educação é a Base. (2017), Brasília: MEC. Disponível em: http://portal.mec.gov.br/index. php?option=com_ docman\&view. Acesso em: 14 fev. 2019.

BRASIL. Decreto $\mathbf{n}^{\mathbf{0}} \mathbf{9 . 7 6 5}$, de 11 de abril de 2019. Institui a Política Nacional de Alfabetização. Disponível em: <http://www.in.gov.br/materia/-/asset_ publisher/Kujrw0TZC2Mb/content/id/71137476/do1e-2019-04-11-decreto-n9-765-de-11-de-abril-de-2019-71137431>. Acesso em: 14 mar. 2020.

CARVALHO, Elma Júlia Gonçalves de. A Educação Básica brasileira e as novas relações entre o Estado e os empresários. Revista Retratos da Escola, Brasília, v. 11, n. 21, p. 525-541, jul./dez. 2017.

CAMINHA, Renato M. Educar crianças: as bases de uma educação socioemocional - um guia para pais, educadores e terapeutas. Nova Hamburgo: Sinopsys, 2014. 
CIERVO, Tassia Joana Rodrigues; SILVA, Roberto Rafael Dias da. A centralidade das competências socioemocionais nas políticas curriculares contemporâneas no Brasil. Revista e-Curriculum, São Paulo, v.17, n.2, p. 382-401 abr./jun. 2019. Disponível em: http://revistas.pucsp.br/index.php/curriculum. Acesso em: 11 dez. 2019.

DALE, Roger. Globalização e Educação: demonstrando a existência de uma "cultura educacional mundial comum" ou localizando uma "agenda globalmente estruturada para a educação"? Educ. Soc., Campinas, vol. 25, no 87, p.423-460, maio/ago. 2004. Disponível em: http://www.scielo.br/scielo.php?. Acesso em: 15 out. 2014.

FRADE, Isabel C. A. da S. Meta 5: Alfabetização. In: OLIVEIRA, João Ferreira de. ARAÚJO, Heleno; GOUVEIA, Andrea Barbosa (org.). Caderno de avaliação das metas do Plano Nacional de Educação: PNE 2014-2024. Brasília: ANPAE, 2018. Disponível em: https://www.anpae.org.br/BibliotecaVirtual/4Publicacoes/CadernoAnlisePNE.pdf. Acesso em: 30 nov. 2019.

FUTATA, Marli Delmonico de Araujo. Breve análise sobre o toyotismo: modelo japonês de produção. Revista Espaço Acadêmico, n. 47, abr. 2005. Disponível em: http://www.espacoacademico.com.br/047/47cfutata.htm. Acesso em: 30 abr. 2005.

GARCIA, Jeferson Diogo. d. A. Política educacional a partir de 1990: uma análise dos fundamentos e a função social da formação para cidadania ativa. Dissertação (Mestrado em Educação) - Universidade Estadual de Maringá, Maringá. 2015.

GASPARIN, João Luiz. Uma didática para a pedagogia histórico-crítica. 3. ed. Campinas, SP: Autores Associados, 2002.

GOLEMAN, Daniel. Inteligência emocional: a teoria revolucionária que define o que é ser inteligente. Tradução Marcos Santarrita. Rio de Janeiro: Objetiva, 2011.

INSTITUTO AYRTON SENNA. Reunião Ordinária CONSED. Belo Horizonte, 17 ago. 2017. Disponível em: http://www.consed.org.br/media/ meeting/599b334e32c51.pdf. Acesso em: 13 fev. 2020. 
INSTITUTO AYRTON SENNA. Alfabetização $360^{\circ}$ na perspectiva da educação integral. 2019?. Disponível em: https://institutoayrtonsenna. org.br/content/dam/institutoayrtonsenna/alfabetizacao360/Folder_ Digital_2019.06.10.pdf. Acesso em: 11 fev. 2019.

LEONTIEV, Alexei. O desenvolvimento do psiquismo. 2. ed. São Paulo: Centauro, 2004.

LEONTIEV, Alexei. Os princípios do desenvolvimento mental e o problema do atraso mental. In: LURIA, Alexander R. et al. Psicologia e pedagogia: bases para psicológicas da aprendizagem e do desenvolvimento. Tradução de Rubens Eduardo Frias. São Paulo: Centauro, 2005.

MACHADO, Maria M. Meta 9: alfabetização e alfabetismo funcional de jovens e adultos. In: OLIVEIRA, João Ferreira de; ARAÚJO, Heleno; GOUVEIA, Andrea Barbosa (org.). Caderno de avaliação das metas do Plano Nacional de Educação: PNE 2014-2024. Brasília: ANPAE, 2018. Disponível em: https:/ / www.anpae.org.br/BibliotecaVirtual/4Publicacoes/CadernoAnlisePNE.pdf. Acesso em: 30 nov. 2019.

MARX, Karl.; ENGELS, Friedrich. A ideologia alemã. Tradução de Álvaro Pina. São Paulo: Expressão Popular, 2009.

PARANÁ. Secretaria de Estado da Educação. Superintendência de Educação. Departamento de Ensino de Primeiro Grau. Currículo Básico Para a Escola Pública do Estado do Paraná. Curitiba: Imprensa Oficial do Estado do Paraná, 1990.

SANTOS, Daniel; PRIMI, Ricardo. Desenvolvimento socioemocional e aprendizado escolar: uma proposta de mensuração para apoiar as políticas públicas. São Paulo: OCDE; Instituto Ayrton Senna, 2014.

SANTOS, Jane Eire Rigoldi dos. Política de avaliações externas: a ênfase na questão das competências cognitivas e socioemocionais. 2015. 170 f. Dissertação de Mestrado em Educação - Universidade Estadual de Maringá, Maringá, 2015.

SAVIANI, Dermeval. Pedagogia histórico-crítica. Campinas: Autores Associados, 2005. 
UNESCO. Educação de qualidade no Brasil. [s/d]. Disponível em: https:/ / pt.unesco.org/fieldoffice/brasilia/education-quality. Acesso em: 14 mar. 2020.

UNESCO. Educação para Todos: o compromisso Dakar (2001). Disponível em: https://pt.slideshare.net/nfraga/educao-para-todos-o-compromisso-dedakar-2000. Acesso em: 13 fev. 2020.

VIEIRA, Juliana Piovesan. Organização do ensino nos anos iniciais: reflexões sobre atividades de leitura. 2012. Dissertação (Mestrado em Educação) Universidade Estadual de Maringá, Maringá, 2012.

VIEIRA. Juliana Piovesan; SANTOS. Jane Eire Rigoldi dos. Alfabetização: uma análise a partir das relações de produção. In: CONGRESSO INTERNACIONAL DE PSICOLOGIA DA UEM. 7., 2018. Anais eletrônicos [...], 2018. Disponível em: https://npd.uem.br/eventos/anais/vistrab/489. Acesso em: 10 fev. 2020.

VIGOTSKI, Lev Semyonovich. A formação social da mente. São Paulo: Martins Fontes, 1998.

VIGOTSKI, Lev Semyonovich. A construção do pensamento e da linguagem. São Paulo: Martins Fontes, 2000.

Jane Rigoldi dos Santos

Doutoranda em Educação (UEM).E-mail: janerigoldi@hotmail.com

Juliana Piovesan Vieira

Doutoranda em Psicologia (UEM). E-mail: jpvieira2@uem.br

Marli Delmonico de Araujo Futata

Doutora em Educação - Professora do Departamento de Pedagogia na Universidade Estadual de Maringá - UEM/CRC.E-mail: mdafutata@uem.br 